\title{
The Efficacy of Cognitive Shock
}

\author{
A Monograph \\ by \\ MAJ Anthony L. Marston \\ United States Army
}

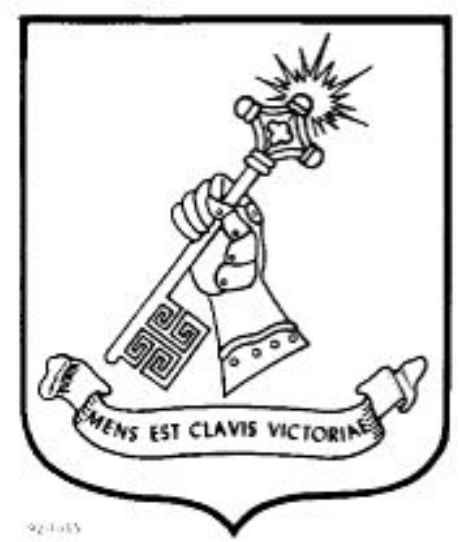

School of Advanced Military Studies

United States Army Command and General Staff College

Fort Leavenworth, Kansas

2015-01

Approved for public release; distribution is unlimited 


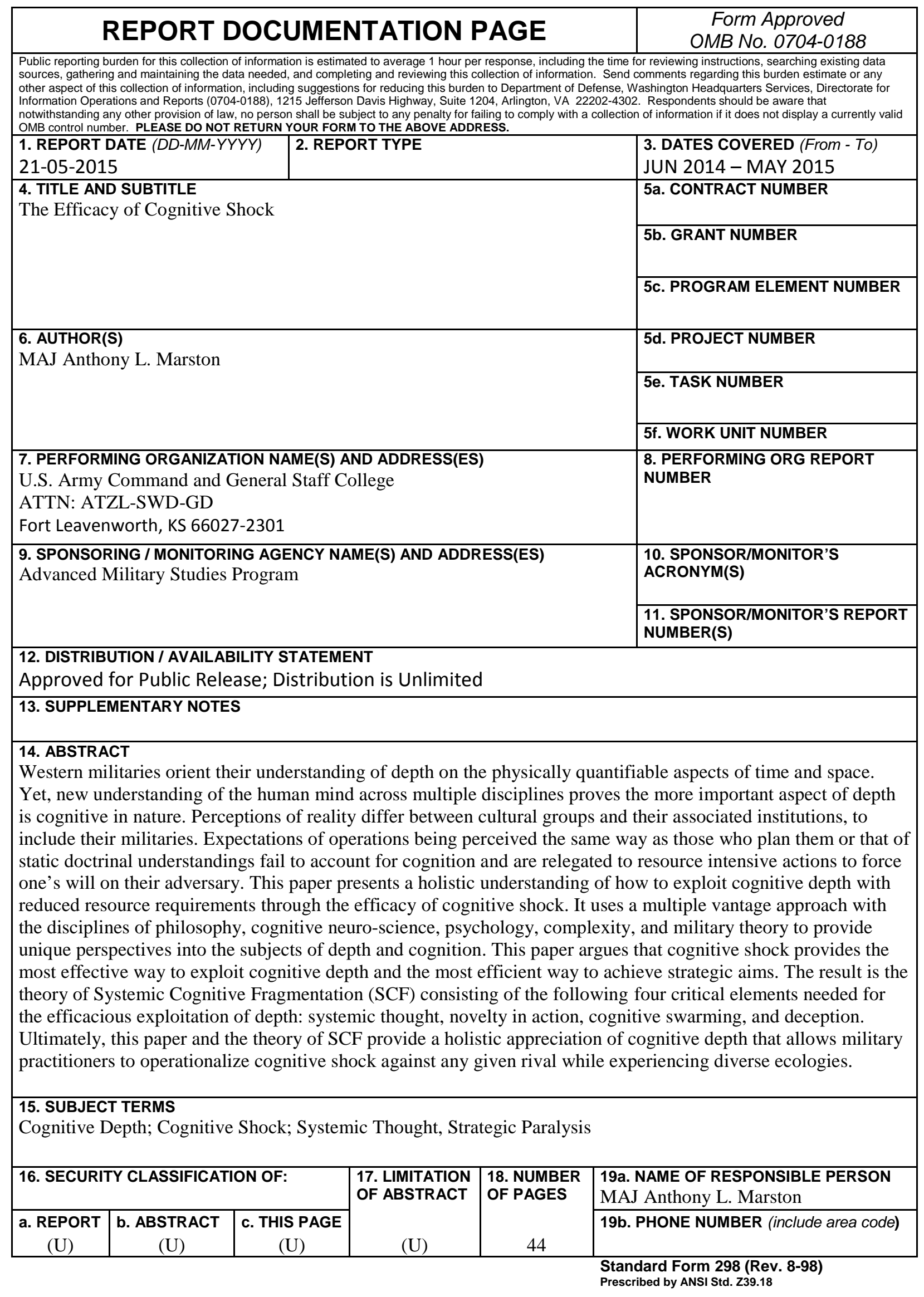




\section{Monograph Approval Page}

Name of Candidate: MAJ Anthony L. Marston

Monograph Title: The Efficacy of Cognitive Shock

Approved by:

, Monograph Director

Alice Butler-Smith, PhD

, Seminar Leader

James MacGregor, COL

, Director, School of Advanced Military Studies

Henry A. Arnold III, COL

Accepted this 21st day of May 2015 by:

, Director, Graduate Degree Programs

The opinions and conclusions expressed herein are those of the student author and do not

necessarily represent the views of the US Army Command and General Staff College or any other governmental agency. (References to this study should include the foregoing statement.) 


\begin{abstract}
The Efficacy of Cognitive Shock, by MAJ Anthony L. Marston, 44 pages.

Western militaries orient their understanding of depth on the physically quantifiable aspects of time and space. Yet, new understanding of the human mind across multiple disciplines proves the more important aspect of depth is cognitive in nature. Perceptions of reality differ between cultural groups and their associated institutions, to include their militaries. Expectations of operations being perceived the same way as those who plan them or that of static doctrinal understandings fail to account for cognition and are relegated to resource intensive actions to force one's will on their adversary. This paper presents a holistic understanding of how to exploit cognitive depth with reduced resource requirements through the efficacy of cognitive shock. It uses a multiple vantage approach with the disciplines of philosophy, cognitive neuro-science, psychology, complexity, and military theory to provide unique perspectives into the subjects of depth and cognition. This paper argues that cognitive shock provides the most effective way to exploit cognitive depth and the most efficient way to achieve strategic aims. The result is the theory of Systemic Cognitive Fragmentation (SCF) consisting of the following four critical elements needed for the efficacious exploitation of depth: systemic thought, novelty in action, cognitive swarming, and deception. Ultimately, this paper and the theory of SCF provide a holistic appreciation of cognitive depth that allows military practitioners to operationalize cognitive shock against any given rival while experiencing diverse ecologies.
\end{abstract}




\section{Contents}

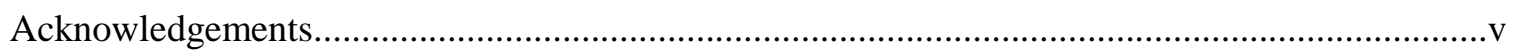

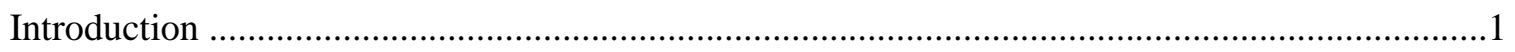

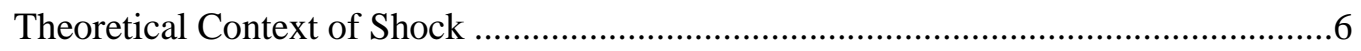

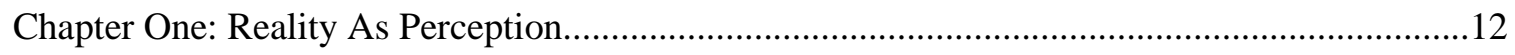

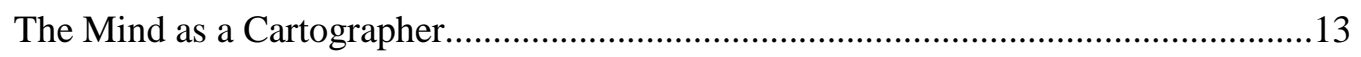

Mental Voids and Gaps...................................................................................

Chapter Two: The Void Between Perceived and Presented........................................................19

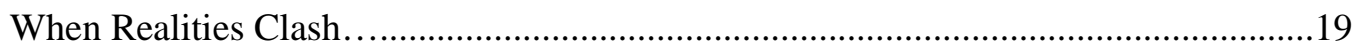

Byproducts of Surprise......................................................................................21

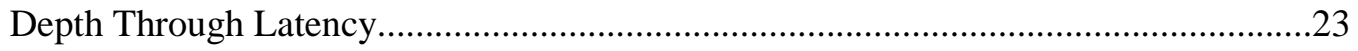

Chapter Three: Systemic Cognitive Fragmentation.............................................................25

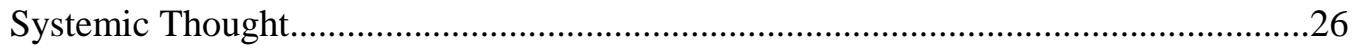

Growing Novelty Out of The Mental Voids...............................................................28

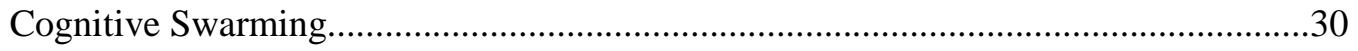

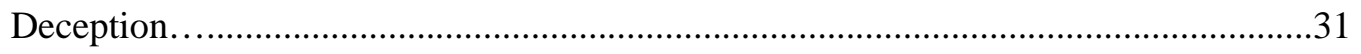

Conclusion: Fragmenting the Doors of Perception.................................................................33

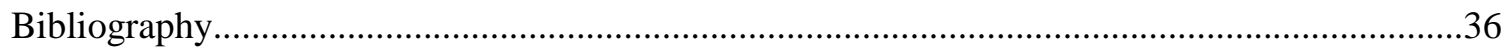




\section{Acknowledgements}

I would like to take this opportunity to acknowledge those who significantly aided in my academic endeavor. I would like to thank the Joint Special Operations University, especially Robert Napela, for funding and assisting in organizing my research trip to Israel. I would also like to thank Dr. Shimon Naveh, Dr. Ofra Gracier, BG Gal Hirsch, BG Gideon Avidor, Dr. Zvi Lanir, Ambassador Reuven Merhav, and COL Reuven Ben-Shalom for their personal time and effort in guiding me in my research. The expertise provided proved indispensible in gaining an understanding of complex concepts and material. Last but not least, I would like to thank my peers who provided a sounding board for ideas, limiting the bad ones while encouraging those ideas with promise. 


\section{Introduction}

Place and distance cease to be of much interest. The mind does its perceiving in terms of intensity of existence, profundity of significance, relationships within a pattern... Space was still there; but it had lost its predominance. The mind was primarily concerned, not with measures and locations, but with being and meaning.

- Aldous Huxley, The Doors of Perception

Any understanding of physical depth is a matter of perception and interpretation. That is not to say there are no quantitative characteristics to time and space. Physical distance can be measured in kilometers, nautical miles, inches, or centimeters. Time elapses in seconds, minutes, hours, or days. However, in spite of being able to achieve the most exact measurements, people interpret and exploit both time and space differently owing to differences in social-cultural norms. For instance, the separation between two neighborhoods within a city may be negligible, as each area can physically blend into the next in ways that are not necessarily entirely perceptible. Chinatown and Little Italy provide examples of ethnically oriented communities within New York City that are visually distinct, yet have far more divergent conceptions of what is expected, appropriate, and necessary functioning within each - despite their spatially contiguity. ${ }^{1}$ While waiting thirty minutes at a restaurant to receive food may seem reasonable, waiting the same amount in a drive-thru is not. Technological advances over the past decade have further affected perceptions of time and space, and the implications of those for the fundamental expectations and behaviors of diverse social groupings. French philosopher Paul Virilio recognized, with the creation of the television and its programming, "everything is always already there, offered to view in the immediacy of an instantaneous transmission." ${ }^{2}$ Viewers watch and digest events occurring in a location on the other side of the world within seconds, ensuring "the greatest

${ }^{1}$ Eviatar Zerubavel, The Fine Line: Making Distinctions in Everyday Life (Chicago: University of Chicago Press, 1993), 7.

${ }^{2}$ Paul Virilio, Lost Dimension, translated by Daniel Moshenberg (Los Angeles: Semiotext(e), 2012), 35. 
distance no longer precludes perception.” ${ }^{3}$ Despite the near instantaneous reception of the information, the television viewer will process events different then those physically experiencing them. The manner in which time and space are processed, interpreted, and utilized remains cognitive.

Yet, western militaries orient their understanding of depth on the physically quantifiable aspects of time and space. Army Doctrinal Reference Publication defines depth as "the extension of operations in time, space, or purpose, including deep-close-security operations, to achieve definitive results." ${ }^{4}$ It goes on to emphasize striking "enemy forces throughout their depth, preventing the effective employment of reserves, command and control nodes, logistics, and other capabilities not in direct contact with friendly forces.” Time retains an inward, self-oriented focus as the doctrinal forms of tempo, momentum, and simultaneity are described in self-referential terms of operating against an enemy. This exploration of depth remains one-dimensional: It fails to account for the reciprocal inter-relationships that define and are inherent in warfare. Since the euphemism "the enemy gets a vote," is engrained in the military discourse, what does that really mean? How does depth change when viewed as a concept - and through the lens of a unique adversary in a unique context? How are the forces' understanding of depth affected by the environment they are operating in and their perceptions of it? These questions begin to produce an appreciation for the multi-dimensionality depth given that how it is appreciated changes according to perspective and context. This leads to a more pertinent question: how can a holistic appreciation of depth - as something that is created through a synthesis of the cognitive and the physical - affect our understanding and conduct of warfare? The answers begin to emerge in the writings of a military theorist nearly one hundred years ago.

\section{${ }^{3}$ Virilio, Lost Dimension, 35.}

${ }^{4}$ Army Doctrine Reference Publication (ADRP) 3-0, Unified Land Operations (Washington, DC: Government Printing Office, 2012), 2-14. 
In the spring of 1919, J.F.C. Fuller wrote a series of articles reflecting on the events that transpired during World War I. Characterizing the engagements during the war as "pitched battles, in which many casualties have been inflicted and sustained,” Fuller warned of both the dangers and ignorance of assuming that brute force is the only way to destroy the enemy’s fighting strength. ${ }^{5}$ While victory may come to the generals who utilize their armies in battles of attrition, the triumph remains trivial because of the large costs in human life and its detriment to future preparedness. In his mind, “A victory, unless it can declare a dividend, is a bad investment.” To further explore the issue of military focus on manpower, Fuller used the analogy of a rifleman stalking his pray. Being wise to the anatomy of his target, he argued, the rifleman takes aim at the head or the heart instead of wasteful shots through the calf of the leg. Even more interesting is the individual with the club that "might induce the rifleman to approach so close to him as to permit of an opportunity arising of using his club as a weapon of surprise under conditions which render it as effective as the rifle.” ${ }^{6}$ It is through surprise that "the whole organization of an attack will become as simple as an individual contest in the open between a man armed with a rifle and a man armed with a club."7 It is the man with the club, untethered from his reliance on technical capability and its associated tactical rules, who is able to exhibit novelty in his actions and cunning in his strategy, and who achieves victory. He is able to accomplish this through his sensitivity to the perceptions and behavioral patterns of his rival which allows him to use their differences rather than trying to mitigate them.

Inherent in Fuller's writing and his theory of strategic paralysis is the understanding that perception and cognition are more critical to military success than brute strength employed in an effort to compel an opponent to capitulate. Forcing one’s will implies meeting guaranteed

\footnotetext{
${ }^{5}$ J.F.C. Fuller, On Future Warfare (London: Sifton Praed \& Co., LTD., 1928), 83.

${ }^{6}$ Ibid., 84.

${ }^{7}$ Ibid.
} 
resistance and the requirement for more resources. Fuller, however, suggests that the creation of surprise presents a more efficient way of achieving desired aims. Implicit in his approach is the disruption of the adversary's cognition, or perceptions of reality. Instead of focusing on purely spatial or temporal aspects of warfare, exploited depth through the induction of surprise is so powerful that latency in action occurs. This latency emerges from cognitive shock and results in the exploitation of cognitive depth through efficient means based on the emerging ecology rather than the more static concepts of force and control. ${ }^{8}$

This paper explores perception of depth and its potential exploitation through an examination of cognitive processes and the nature of shock. A multiple vantage approach is used with the disciplines of philosophy, cognitive neuro-science, psychology, complexity, and military theory providing unique perspectives into the subjects of depth and cognition. The resulting synthesis creates a holistic understanding of how perception is created and how cognitive shock manifests. ${ }^{9}$ This paper argues that cognitive shock provides the most effective way to exploit cognitive depth and the most efficient way to achieve strategic aims. It provides a framework to facilitate the exploitation of cognitive depth in the theory of Systemic Cognitive Fragmentation (SCF).

${ }^{8}$ Ecology is defined by Merriam-Webster as the totality or pattern of relations between organisms and their environment. Its use in this context is meant to denote the reciprocity inherent in the interaction between a group and its surroundings, as well as to negate the tendency to overlook this connection when using the term of an operational environment. When thinking systemically, it is important to appreciate the relational aspect of a given system and not view it as dependent variables. Ecology serves as a reminder to the inherent interconnectivity.

${ }^{9}$ This paper does not seek to provide an alternative theory of cognitive shock as it remains sound and other theoretical works cover the topic. Two theories provide the most coherent frameworks for understanding cognitive shock. Shimon Naveh's work on Systemic Operational Design (SOD) and Systemic Design Inquiry (SDI) focuses on how to create a paralyzing effect on rivals through the concept of operational shock. Zvi Lanir's concept of Fundamental Surprise presents an understanding of the result of when a surprise that effects core beliefs occurs and how to establish a mindset that decreases the likelihood of this occurring. Both of their concepts appear throughout the paper. 
The theory of SCF provides a holistic appreciation of cognitive depth that allows military practitioners to operationalize cognitive shock against any given rival while experiencing diverse ecologies. BG Dr. Shimon Naveh defines systemic as "the employment of systems thinking and practice to construct systems models (theories) rationalizing unique emergences (complex phenomena), while observing the 'world' (relevant context) outside the prevailing institutional paradigm.” ${ }^{10}$ Systemic within SCF provides a conceptual reference for understanding an emerging ecology through a holistic means that prevents the loss of context and remains unbiased by established organizational thought. Cognitive denotes the very human characteristics inherent in warfare and the importance of appreciating perception as cognitive and therefore unique. It also proposes that physical manifestations of conflict are simply reflections of combatants' understanding and interpretation of time and space, and its potential in any given context. The idea of fragmentation reflects the core concept of the Soviet Deep Operations Theory where a force strikes throughout the depth of an adversary, fragmenting the force and creating operational shock (udar). SCF then consists of four essential elements to highlight the nature of and provide insight into the efficacy of exploiting cognitive depth through systemic thought, novelty in action, cognitive swarming, and deception. Systemic thought relies on a holistic examination of the situation that does not seek to oversimplify the complex, rather to appreciate the interconnectedness that exists. It provides the way to understand the emerging ecology, the rival's system logic within it, and how appropriate the existing institutional norms are given the situation. Within the developed systemic thought lies the ability to understand what might be novel and as a result of its use increases the chances of cognitive shock occurring. Cognitive swarming addresses the need to present multiple novelties in order to overwhelm and fragment the rival's logic, creating cognitive shock and creating additional depth through latency of rival coherent action. SCF is explored further throughout the paper. Ultimately, SCF seeks to explore

\footnotetext{
${ }^{10}$ Shimon Naveh, “Systemic Operational Design 2009” PowerPoint presentation, 6.
} 
the relevance of cognitive depth and how its exploitation represents the efficaciousness of cognitive shock towards achieving strategic aims.

Prior to the exploration of cognitive depth and its potential for military exploitation, an exploration of the existing theoretical context of shock will identify the gaps in the current military theories as it relates to its holistic understanding. These gaps create the focus areas examined in the body of the monograph with the first chapter examining how an individual perceives the world through the creation of mental maps. Social interaction with larger sociocultural groups further influences the individual's perception of reality and results in a collective understanding of depth cognitively. Once an understanding of how individuals and groups establish their reality, the second chapter explores how this understanding differs from the world around them and can lead to surprise, as the experienced reality is different from the perceived one. ${ }^{11}$ The chapter further explores cognitive shock as latency in an individual or group's ability to learn or effectively act. With the understanding of the actual manifestation of cognitive shock, the third chapter expands on the theory of systemic cognitive fragmentation through the use of a systemic examination of the environment. ${ }^{12}$ Through a holistic approach to framing the emerging ecology, the rival logic's cognitive gap in relation to how they understand the friendly force's strategy becomes apparent and allows for the identification of opportunities for action that correspond with the greatest potential for creating cognitive shock. ${ }^{13}$ The conclusion discusses the implications of SCF and areas that will require further exploration.

Theoretical Context of Shock

${ }^{11}$ Emiliano Lorini and Cristiano Castelfranchi, “The Cognitive Structure of Surprise: Looking for Basic Principles,” Topoi 26, no. 1 (March 2007), 133.

${ }^{12}$ Shimon Naveh, interview by author, Tel Aviv, January 22, 2015.

${ }^{13}$ Ibid. 
The concepts of surprise, shock, and paralysis are common themes in military literature. However, when other theories are compared to these concepts, patterns of thought among the authors become evident and gaps that are left unexplored become easily identifiable. Everything from their intended meaning of surprise to the actions required to achieve it vary. While numerous theorists discuss the ideas of shock in warfare, the literary review will focus on the theories that provide the most comprehensive and coherent exploration of the phenomenon, as well as those ideas that have had the most influence on contemporary, western military thought about shock.

J.F.C. Fuller's idea for the use of surprise to create a paralytic condition in the enemy was not a new concept at the time, as numerous examples in history provided situations where the destruction of an army resulted from its inability to provide a synchronized fight. However, the way in which Fuller conceptualized what he termed "brain warfare" as the rendering of an army incapable of exercising its power of command was revolutionary in its visualization of warfare. Based on Spenser Wilkinson’s 1913 description of the German general staff as a brain, Fuller envisioned brain warfare as directly targeting the headquarters of the enemy, disrupting their ability to provide guidance command and control while causing paralysis for the rest of the army ${ }^{14}$ In the resulting paralytic state, the enemy faltered in providing any coherent resistance while an efficiently sized force achieved the ultimate strategic goal of destroying the enemy’s fighting strength. ${ }^{15}$ While the idea of paralysis is important, even more critical to Fuller's ideas is the creation of surprise "by novelty of action."16

Fuller's conceptualization of brain warfare, the concept of novelty in action, and its potential for strategic paralysis provided the foundation for a majority of the theories that

\footnotetext{
${ }^{14}$ Spenser Wilkinson, The Brain of an Army: A Popular Account of the German General Staff (London: Constable \& Company LTD, 1913), 97.

${ }^{15}$ Fuller, On Future Warfare, 83.

${ }^{16}$ Fuller, On Future Warfare, 94.
} 
followed. While its merits are evident in its appreciation for the need of both a new logic and new form of warfare, there are aspects missing from Fuller's theory. For instance, he focuses on the function of two vehicles, the tank and airplane, and their ability to redefine the idea of maneuverability. Writing in 1919, Fuller proposed the use of those new technologies in a novel manner based on his appreciation that "he who grasps the full meaning [emphasis added] of this change, namely, that the earth has now become as easily traversable as the sea, multiplies his chances of victory to an almost unlimited degree.” ${ }^{17}$ The resulting form of warfare he proposes is indeed novel, but only during its initial use. Once the military integrated tanks and airplanes into warfare, the potential for militaries to generate surprise using Fuller’s specific form were limited because the resulting use presented a set pattern after multiple iterations. Although Fuller argues surprise also takes the form of "the impossibility of counteraction," this potentially creates the conditions he originally argues against in which control of the enemy is focused on attrition through numbers. His notion of novelty in action remains critical, but an overarching theory of surprise should transcend a point in time and explain the phenomena in all contexts.

A maturing and more thorough understanding of shock materialized further east in the Soviet Union. The now famous names of Tukhachevsky, Triandafillov, and Isserson formulated the theory of Deep Operations. Born out of the bloody stalemates of World War I and the Bolshevik Revolution, their theory represented a paradigm shift in the conception of warfare. In conjunction with the visualization of the operational level of war was the concept of udar (operational shock). Udar represented the ultimate goal for the Soviet actions on the battlefield, where simultaneous actions against a broad front of defensive positions would facilitate the penetration of a large force to cause chaos through the targeting of the enemy's rear and reserve forces. Such an approach would fragment the cohesion of the army and cause an operational shock. A product of multiple theoretical works, the Provisional Field Regulations for the Red

\footnotetext{
${ }^{17}$ Ibid., 91.
} 
Army (PU-36) incorporated the prevailing ideas of depth and operational shock into one document. It recognized that "Red Army combat operations will always be oriented toward the annihilation of the enemy.” ${ }^{18}$ This closely resembled Fuller's assertion that "the strategical object of war is the destruction of the enemy's fighting strength." ${ }^{19}$ To achieve this, tactical actions in depth were to result in "the destruction of the enemy's animate forces and materiel” as well as "the impairment of his morale and ability to resist." ${ }^{20}$ Udar represented a depth of operations not previously captured in a coherent theory, creating conditions for paralytic characteristics to occur throughout a given rival's force. ${ }^{21}$ It also allowed for limited novelty in the choosing of both the location and size of force used to penetrate enemy defenses. However, udar remained industrial in nature, by focusing on the mechanical manifestation of shock without an appreciation for its cognitive aspects. ${ }^{22}$

The next evolution in what could be called a theory of shock occurred with the American John Warden. Warden's postulations focused on the conduct of air campaigns, primarily at the operational level in a given theater of war. ${ }^{23}$ While recognizing the importance of a joint effort between all of the services, he saw the air force as critical to strategic success through the effective targeting of centers of gravity. Describing centers of gravity as "the point where the enemy is most vulnerable and... an attack will have the best chance of being decisive,” Warden believed that theater operations must focus on "defeating the enemy by striking decisive blows"

${ }^{18}$ Provisional Field Regulations for the Red Army (PU-36), 1936, 2.

${ }^{19}$ Fuller, On Future Warfare, 83.

${ }^{20} \mathrm{PU}-36,2$.

${ }^{21}$ In relation to Udar, depth represented the synchronization of actions in both time and space. Operational shock required the simultaneous execution of tasks throughout the battle space to ensure the adversary were overwhelmed throughout the depth of its defenses.

${ }^{22}$ Shimon Naveh, interview by author, Tel Aviv, January 18, 2015.

${ }^{23}$ John A. Warden III, The Air Campaign (Lincoln, NE: toExcel, 2000), 4. 
against these points. ${ }^{24}$ He used Fuller's metaphor of the army as a body and brain to emphasize the importance of targeting the command and control capability of the enemy. His now famous five-ring model visualized the army’s respective parts in concentric rings with leadership, or the brain, at the center. ${ }^{25}$ Airpower provided the means by which militaries could bypass the main defenses of the enemy and target what Warden believed was the army's primary center of gravity in its leadership. Paralysis would follow through the disruption and destruction of the command nodes, resulting in the army's inability to coordinate any effective resistance. Although the focus on the leadership as a center of gravity presented a unique addition to the idea of shock, it lacked an appreciation for complexity and systemic thought - both of which would come later in the work of John Boyd. Warden's understanding of shock also lacked an appreciation of the role of cognition in its manifestation.

John Boyd emerged as a leading military theorist as he incorporated complex systems theory into an understanding of shock. Reaching the conclusion that warfare was non-linear in nature due to the existence of complex adaptive systems, he postulated a general strategic aim: “Diminish adversary’s capacity while improving our capacity to adapt as an organic whole, so that our adversary cannot cope while we can cope with events/efforts as they unfold.” ${ }^{26}$ Boyd understood the power of novelty in disrupting an adversary’s ability to predict actions and to create a strategy to counter. His thinking showed an appreciation for the cognitive aspect of warfare in his conceptualization of the competing strategies of the friendly element and the adversary. It also recognized the evolutionary nature of warfare owing to the reciprocal and dialectical relationship that exists between opposing forces engaged in conflict over time. From

\section{${ }^{24}$ Ibid., 7.}

${ }^{25}$ James D. Kiras, Special Operations and Strategy: From World War II to the War on Terrorism (New York: Routledge, 2006), 25.

${ }^{26}$ Frans P.B. Osinga, Science, Strategy and War: The Strategic Theory of John Boyd (New York: Routledge, 2007), 101. 
his understanding, it would be possible to create surprise and induce paralysis by interrupting the decision cycle of the adversary through novel means while at the same time adapting to the changing circumstances. This would result in achieving a position of advantage by the force that exploited the cognitive strategy of its rival. Boyd emphasized the targeting of weaknesses in an adversary - known as non-cooperative centers of gravity - to disrupt its strategy and to cause hesitation in their actions. ${ }^{27}$ While his model of the Orient Observe Decide Act (OODA) loop, and its role in facilitating shock, represented the most comprehensive theory of shock created to this point, it is missing a critical component. Boyd's appreciation of cognition is only partial, as the theory does not reflect each individual and their respective socio-cultural group’s varying perception of reality. With different perceptions of reality come different understandings of what is surprising and what might create paralysis. What might be shocking to the American military is not necessarily the same for an insurgent group with a different cultural background. A complete theory of shock must include the knowledge of varying perceptions of reality and how these perceptions manifest themselves within a rival system.

\footnotetext{
${ }^{27}$ Ibid., 146.
} 


\section{Chapter One}

\section{Reality As Perception}

There are, in other words, no perfect maps - just maps that (more-or-less) perfectly capture our understanding of the world at discrete moments in time.

- Uri Friedman, “12 Maps That Changed the World,” The Atlantic

The creation of a map is the cartographer's way of capturing everything that he has learned about a given spatial area at a particular moment in time. The images he captures represent the information he gathered and processed for the given purpose of the map while still meeting the guidelines provided through social norms or the cartographer's certifying element. It is important to remember that even the most detailed map only expresses the visualization of the world framed at a given movement of time. Shorelines may recede or grow with the lunar cycle or other factors. Political turmoil can change boundaries between nations, sometimes changing the socially accepted identity of the states involved. However, in spite of the inherent inaccuracy of the cartographer's creation it still fulfills its necessary function of providing a way for people to navigate the world around them.

The brain provides the same function for the individual as the cartographer, as its mental maps are attempts at depicting reality through perception. Using the concepts of leading experts, this chapter, explores how an individual develops a perception of reality through his interactions in the world resulting in the creation of mental maps. With time and social interaction, the brain refines mental maps and uses them to construct heuristics to facilitate quick reactions in certain situations. It is through social interaction that individual perceptions permeate throughout a sociocultural group, creating a shared perception of the world. A multidisciplinary appreciation of the individual and sociocultural creation of perceived realities is critical to the subsequent chapter's discussion on surprise. More importantly, it establishes the importance of cognition in developing the perception of the world and the concept of depth. 
The Mind as a Cartographer

The body and brain are constantly at work capturing, categorizing, and evaluating information they receive through sensory organs. What it interprets as information is not simply limited to visual data but includes auditory, visceral, and tactile inputs from both internal and external processes. ${ }^{28}$ When walking through a park on a pleasant day, the feel of the sun's warmth on the skin, the sweet smell of newly blooming flowers, and the sound of birds chirping all represent information processed through the body and manifesting as momentary patterns of stimulated neurons. ${ }^{29}$ Each input forms a singular image within the mind representative of the momentary pattern, allowing for recall later if the mind needs to cross-reference a previous experience. A slightly more complex action also occurs as all of the images from a specific moment are gathered. Acting as a cartographer, the mind combines the frozen images of information into a mental map representative of how the mind processed the combination of all inputs. ${ }^{30}$ Over time, each map slowly adapts with additional processed information and experiences. More importantly, the mind uses these mental maps to navigate daily life. Instead of contemplating for long periods on how to drive through a city, the mind refers to habitualized actions already engrained that may relate to an individual's preference for scenic routes or the fastest route possible. ${ }^{31}$

Another critical aspect related to the development of a perceived reality is an individual's social interaction with others. Sociologist Eviatar Zerubavel put it best when he asserted, "Mental

${ }^{28}$ Antonio Damasio, Self Comes to Mind: Constructing the Conscious Brain (New York: Pantheon Books, 2010), 18.

${ }^{29}$ Ibid.

${ }^{30}$ Ibid., 39.

${ }^{31}$ Peter Turchi, Maps of the Imagination: The Writer as Cartographer (San Antonio: Trinity University Press, 2004), 28. 
reality... is deeply embedded in social reality." 32 It is nearly impossible to "exist in everyday life without continually interacting and communicating with others." ${ }^{33}$ Not only is the mind creating mental maps of these encounters, but previously created maps are refined as well. Language is critical to these interactions. It is "capable of becoming the objective repository of vast accumulations of meaning and experience, which it can then preserve in time and transmit to following generations." ${ }^{34}$ Words convey ideas from the past and present, providing rhetoric where none previously existed as social convention delineates the boundaries between different concepts. ${ }^{35}$ For example, institutions created the significance of a stop sign, which lacks meaning outside of the established context. It symbolizes socialized knowledge, informing an individual to stop their conveyance prior to reaching the sign. Language provides the means to create symbols, “appresenting them as objectively real elements in everyday life.”36 It becomes "essential constituents of the reality of everyday life and of the commonsense apprehension of this reality." ${ }^{37}$ This leads to a tendency to consider purely social entities as natural. ${ }^{38}$ The individual is enabled to further construct mental maps in ways that provide coherence in the mind and facilitate the communication of each construct to others. Reality takes on a sociocultural form with perception existing within the established and legitimized social knowledge. While each individual still maintains a specific perception of what reality is, it is now more shared than not.

\footnotetext{
${ }^{32}$ Eviatar Zerubavel, The Fine Line: Making Distinction in Everyday Life (Chicago: The University of Chicago Press, 1991), 32.

${ }^{33}$ Peter L. Berger and Thomas Luckmann, The Social Construction of Reality: A Treatise in the Sociology of Knowledge (New York: Anchor Books, 1967), 23.

${ }^{34}$ Ibid., 37.

${ }^{35}$ Zerubavel, The Fine Line: Making Distinction in Everyday Life, 62.

${ }^{36}$ Berger, The Social Construction of Reality, 39.

${ }^{37}$ Ibid.

${ }^{38}$ Zerubavel, The Fine Line: Making Distinction in Everyday Life, 27.
} 
Homeostasis provides the reason for accepting a shared reality with others of a social group. Humans biologically seek homeostasis and the continuation of behavior oriented to sustaining life. However, interaction with the world has a profound effect on the body, causing an "inherent instability," leading to a disruption in the ability to continue the current way of thinking or acting. ${ }^{39}$ This results in "explicit efforts at sensemaking” as the individual reevaluates his interpretation of the situation and the appropriate action. ${ }^{40}$ This drives humans to create stable environments that reduce the chances of negative interactions with their surroundings. Through cooperation with other humans, social order often provides the most efficient means of stabilizing an environment. Dependence on others may seem counterintuitive to individual survival. However, it is in the accomplishment of tasks and roles outside of a person's abilities that is critical. Actions and activities essential to survival become habitualized within the group and create critical roles to ensure proper execution of required actions. ${ }^{41}$ It is within this habitualization of activities and actions that heuristics emerge and mental maps find their primary function as guides for navigating perceived reality.

Daniel Kahneman defines a heuristic as “a simple procedure that helps find adequate, though often imperfect, answers to difficult questions." ${ }^{42}$ Serving as "simplifying strategies, or 'general rules of thumb,'” they allow for rapid evaluation and action within a given situation without much thought. ${ }^{43}$ Heuristics represent a habitualized action, often legitimized as social

${ }^{39}$ Berger, The Social Construction of Reality, 52.

${ }^{40}$ Karl E. Weick, David Obstfeld, and Kathleen M. Sutcliffe, "Organizing and the Process of Sensemaking,” Organization Science, Vol. 16, No. 4, July-August 2005, 409.

${ }^{41}$ Berger, The Social Construction of Reality, 54.

${ }^{42}$ Daniel Kahneman, Thinking, Fast and Slow (New York: Farrar, Straus and Giroux, 2011), 98.

${ }^{43}$ Stephen J. Gerras, “Thinking Critically About Critical Thinking: A Fundamental Guide for Strategic Leaders,” US Army War College, August 2008, 13. 
knowledge of a historically proven method and further implying "that the action in question may be performed again in the future in the same manner and with the same economical effort." ${ }^{44}$ Instead of designing a new way to make toast every time, mental maps retain a learned process, allowing an individual to make toast without much effort. Cognitively, it minimizes the amount of decisions required and saves mental capacity for more difficult situations. Time and effort required decrease as mental maps facilitate quick execution of cognitive processes on an almost unconscious level. ${ }^{45}$ However, reduced time to process also means less scrutiny of the information processed. When ecology associated with a situation fits roughly into an established mental map and associated heuristic, organizations miss critical information contradicting perception. This creates the conditions for surprise to occur. Deception in the form of reaffirming mental models and heuristics becomes a vital magnifier of cognitive shock for its practitioners, concealing his actions to increase the disparity between his adversary's perceived and that of the actual reality.

Mental Voids and Gaps

It is important to understand that created mental maps are not necessarily reflective of the true reality for a given situation due to the mind's processing of the input. For instance, there is no absolute concept of color in the world. ${ }^{46}$ While tools can accurately measure a specific

${ }^{44}$ Berger, The Social Construction of Reality, 53.

${ }^{45}$ Daniel Kahneman discusses extensively the concept of System 1 and System 2 thought in his book, Thinking, Fast and Slow. While not mutually exclusive, System 1 represents the more automatic and unconscious cognitive activities while System 2 symbolizes more deliberate and creative processes. For the purposes of the heuristic discussion, System 1 represents the mental map formed for quick use while System 2 executes the heuristic for a given situation.

${ }^{46}$ Ginger Campbell, MD, host, "Interview with Dr. Michael Graziano, Author of Consciousness and the Social Brain,” Brain Science Podcast, April 15, 2014, accessed February 13, 2015, http://brainsciencepodcast.com. 
wavelength of light, the individual's interpretation is actually independent of this measurement. ${ }^{47}$ Instead, the experience of a color corresponds to a specific pattern of activity in the nervous system and the related mental map associated with color acknowledgement. ${ }^{48}$ If presented with the color green, it might be more appropriate to understand that there is an "inner, subjective awareness of green” rather than a true green. ${ }^{49}$ The disconnect between the perception of what reality is and true reality is often a result of the mind's limited time and computing power to fully comprehend and map its surroundings. ${ }^{50}$ Zerubavel identifies the resulting difference of the perceived and true reality as “mental gaps” purposefully created to delineate and compartmentalize information in a manner necessary to process it without too much effort. ${ }^{51}$

The mind provides meaning to the things it perceives through placement into socially defined categories. ${ }^{52}$ Each category establishes a simple and quick way for an individual to determine how to treat or react to something. Simple appreciations for the world emerge out of complexity and result in a perception of control. In military discussions, this reflects the manner in which warfare is often contemporarily referred to as either conventional or unconventional. Implications for general approaches exist with each, providing a socially accepted reference for perceiving events. The need to create discrete entities is so great that organizations create special categories when something falls outside of the socially established parameters. ${ }^{53}$ When warfare

\footnotetext{
${ }^{47}$ Humberto R. Maturana and Francisco J. Varela, The Tree of Knowledge: The Biological Roots of Human Understanding, translated by Robert Paolucci (Boston: Shambhala, 1998), 22.

${ }^{48}$ Ibid.

${ }^{49}$ Michael S. A. Graziano, Consciousness and the Social Brain (New York: Oxford University Press, 2013), 41.

${ }^{50}$ Campbell, "Interview with Dr. Michael Graziano, Author of Consciousness and the Social Brain.”

${ }^{51}$ Zerubavel, The Fine Line: Making Distinction in Everyday Life, 21.

${ }^{52}$ Ibid., 5.

${ }^{53}$ Ibid., 6.
} 
takes on characteristics common to both conventional and counter-insurgency methods, it receives the label of hybrid warfare.

There is an inherent risk in the creation of discrete entities that remove understanding from context. While the attempts to bring order to the perceived world might make logical sense, this process can quickly lead to oversimplification. Categorization removes the uniqueness of a thing during its original sensemaking, which also removes the context associated with it. A group put into the category of 'enemy' is evaluated and acted against without regard for the ways in which it might not fit neatly into the grouping. This removes options for the engagement with the group and oversimplifies the complexity of the situation. Even more troubling is when previous activities are deemed "successful” or "the right way" without the needed context to assist in the qualification of the event. This can lead to methodism in which an organization utilizes a course of action in a different situation then its original use and its benefits do not necessarily show in the current environment. ${ }^{54}$ It is when the established mental maps and their associated heuristics do not reflect the emerging ecology accurately that cognitive depth becomes vulnerable to fragmentation and exploitation. Cognitive surprise and its more dangerous manifestation of cognitive shock increase in likelihood of occurrence. Systemic cognitive fragmentation seeks to create the circumstances for this to occur in a rival, allowing for the full exploitation of his cognitive depth.

${ }^{54}$ Dietrich Dorner, The Logic of Failure: Recognizing and Avoiding Error in Complex Situations (New York: Metropolitan Books, 1996), 170. 


\section{Chapter Two}

\section{Using Old Maps to Navigate the Present}

On the other hand there are experiences which jar with the mental models in some way, causing dissonance or cognitive conflict, so that the mental model has to be 'accommodated' to the new data. Categories and knowledge have to be redefined, new categories and links made. If changes are significant, further disturbances in the mental models may occur even without further data, in order for 'a greater equilibration' to be achieved.

- Mundher Adhami, “Cognitive and Social Perspectives on Surprise.”

Unfortunately for humans, mental maps and their associated unconscious cognitive processes do not "generate a warning signal” when they become unreliable. ${ }^{55}$ Instead, the realization only occurs after the incapability between perceived and presented realities is apparent. Individuals and organizations experience surprise cognitively and, in some circumstances, the more debilitating nature of shock manifests in the inability to react. This chapter explores the concept of cognitive surprise based on the previous chapter's understanding of perceived reality's creation in order to understand how it affects cognitive depth. An appreciation for what surprise is and how it affects the mind will establish its negative effect of disrupting cognitive process and its positive facilitation of learning. A further exploration into the difference between surprise and shock will serve as another building block towards creating the systemic cognitive fragmentation theory.

\section{When Realities Clash}

Cognitive psychologists Emiliano Lorini and Cristiano Castelfranchi define surprise as "the automatic reaction to a mismatch. It is a (felt) reaction / response of alert and arousal due to an inconsistency (discrepancy, mismatch, non-assimilation, lack of integration) between an incoming input and our previous knowledge, in particular an actual prediction or a potential

\footnotetext{
${ }^{55}$ Daniel Kahneman, Thinking, Fast and Slow (New York: Farrar, Straus and Giroux,
} 2011), 416. 
prediction." ${ }^{56}$ According to this definition, the information received through sensory organs does not fall into a predetermined category and instead lies within the area of mental void. There exists a difference between the established perception of reality captured in various mental maps and the presented reality. Zvi Lanir further distinguishes the idea of surprise through an exploration of the level of mismatch between the expected and unexpected. He describes two different types of surprise: situational and fundamental. ${ }^{57}$ Situational surprise relates to what Lorini and Castelfranchi call a mismatch-based surprise in that there is a "conflict between a perceived fact and a scrutinized representation." ${ }^{58}$ While the incoming input does not reflect the established mental map, the mismatch is not significant enough to alter the base of the perception and the individual's overall understanding of themselves and the environment. ${ }^{59}$

Fundamental surprise relates to the idea of astonishment or surprise in recognition where an organization attempts to process input despite the perception of its implausibility ${ }^{60}$ It is "more powerful and extensive” than situational surprise because it causes a complete and "holistic reexamination” of self-perceptions in relation to the emerging ecology ${ }^{61}$ While the occurrence of an event potential of creating situational surprise is predictable, the timing is usually not. For the fundamental surprise, very little is understood about the events that might cause it to occur, making prediction and preparation for one even more difficult. Nassam Taleb acknowledges three

\footnotetext{
${ }^{56}$ Emiliano Lorini and Cristiano Castelfranchi, “The Cognitive Structure of Surprise: Looking for Basic Principles,” Topoi 26, no. 1 (March 2007): 133.

${ }^{57}$ Zvi Lanir, “Fundamental Surprises,” PhD diss., University of Tel Aviv, accessed November 01, 2014, http://csel.eng.ohiostate.edu/courses/ise817/papers/Fundamental_Surprise1_final_copy.pdf.

${ }^{58}$ Lorini and Castelfranchi, “The Cognitive Structure of Surprise,” 134.

${ }^{59}$ Lanir, "Fundamental Surprises."

${ }^{60}$ Lorini and Castelfranchi, "The Cognitive Structure of Surprise,” 134.

${ }^{61}$ Lanir, "Fundamental Surprises.”
} 
characteristics to such an event: rarity, extreme impact, and retrospective predictability ${ }^{62}$ Each instance of fundamental surprise provides a rarity that defies expectations and falls outside of established mental maps. The realized disparity profoundly impacts those experiencing the event, shaking the core of their perceived reality. Once the event is complete or at least recognized, the tendency exists for humans and their minds to "concoct explanations for its occurrence after the fact, making it explainable and predictable.”63 Images and boundaries captured on mental maps shift with the new understanding or find reinforcement when the input is denied. The choice in either reinforcement or change revolves around the real benefit of surprise: potential for learning.

\section{Byproducts of Surprise}

As Mundher Adhami suggests in the chapter's epigraph, induced surprise possesses the potential to facilitate change in the established models - or mental maps. As individuals are "taken aback" through the presentation of an anomaly, an opportunity to resolve the anomaly exists. The process of resolution and the reordering of mental maps amounts to learning. Surprise affords access to the map and carries with it a "mutative potential," allowing the mind to adapt the striated lines of knowledge previously captured. ${ }^{64}$ The events provide the first step in the process of discovery through the exposing of existing mental gaps, emphasizing the differences in perception and the presented reality ${ }^{65}$ The second step rests with the individuals and organizations to not only recognize the mismatch, but to properly process the information and adapt existing mental maps to further address the void. Situational surprise exhibits an increased

\footnotetext{
${ }^{62}$ Nassam Nicholaus Taleb, The Black Swan: The Impact of the Highly Improbable (New York: Random House Trade Paperbacks, 2010), xxii.

${ }^{63}$ Ibid. More," 730.

${ }^{64}$ Gary Taerk, "Moments of Spontaneity and Surprise: The Nonlinear Road to Something

65Jonathan E. Adler, “Surprise,” Educational Theory 58, no. 2, 2008, 149.
} 
potential to motivate the search for a better, internal understanding instead of an authority figure providing an external mandate. ${ }^{66}$ Fundamental surprise, however, presents more of a challenge for an organization to facilitate timely learning if it occurs at all. This type of surprise challenges perceived reality at the core level, removing the reference needed to learn and adapt quickly. Instead, the situation requires the organization to start from scratch, building the basic images and mental maps for the emerging ecology.

Socially, legitimized knowledge provides the base for mental maps and the lens for the perception of the world. Fundamental surprise directly targets this base, making the "routines of everyday life” problematic as the mental gap widens. ${ }^{67}$ The problematic now threatens the stability and potential validity of the organization with the fear of increased chaos and complete loss of control. ${ }^{68}$ Put in this situation, they attempt to incorporate the problematic back into the already established perception of the world in order to regain control. ${ }^{69}$ The event associated with the fundamental surprise takes on a reverse predictability and the explanation for the lack of foresight is conveniently associated with the previous mental maps. When this technique fails, it is even easier for those that oversee the organization to blame lower echelons for the failure to properly predict and correct. ${ }^{70}$ The drive to act, rather than reflect, overrides the learning process and recreates the situation where the organization is "generally blind to itself."71 This exacerbates the fragility to fundamental surprise in the future. To correct this tendency, Lanir suggests,

\footnotetext{
${ }^{66}$ Ibid.

${ }^{67}$ Peter Berger and Thomas Luckman, The Social Construction of Reality: A Treatise in the Sociology of Knowledge (New York: Anchor Books, 1967), 25.

${ }^{68}$ Nassim Nicholas Taleb, Antifragile: Things That Gain From Disorder (New York: Random House, 2014), 5.

${ }^{69}$ Berger, The Social Construction of Reality, 26.

${ }^{70}$ Lanir, “Fundamental Surprises.”

${ }^{71}$ Humberto Maturana and Francisco J. Varela, The Tree of Knowledge: The Biological Roots of Human Understanding (Boston: Shambhala, 1998), 24.
} 
"Instead of conceptualizing surprise only as something that needs to be prevented, we might view surprises as opportunities to learn about ourselves.”72 For the military planner, there is a desire to delay the learning process to reap the benefits of surprise on a rival. This is where cognitive shock and its efficacy differ from surprise.

Depth Through Latency

While surprise brings with it the possibility to learn and adapt the perceptions of reality, cognitive shock seeks to temporarily block thought and learning processes from occurring. Psychologist Gernot Horstmann understood that surprise "triggers certain changes, the most important ones being the interruption of ongoing cognitive and motor processing, the focusing of attention towards the surprising event, and the feeling of surprise.”73 The disruption of the ongoing processing is ultimately the desired effect of operational shock, creating a situation in which the rival is unable to carry out their current strategy or maneuver forces in a coherent manner. More succinctly, it facilitates "a consequential state of a fighting system which can no longer accomplish its aims.” ${ }^{74}$ In order to disrupt cognitive functions in this manner, multiple actions must occur against the cognitive depth of the rival.

For Soviet military theorist Georgii Isserson, depth was "the very essence of the evolving modern operation, and it is this essence that accounts for the operation's enormous intensity."75 If ignored, "an operation is deprived of its essence and becomes historically conservative, failing to

${ }^{72}$ Lanir, "Fundamental Surprises.”

${ }^{73}$ Gernot Horstmann, "Latency and Duration of the Action Interruption in Surprise," Cognition and Emotion 20, no.2 (2006), 245.

${ }^{74}$ Shimon Naveh, In Pursuit of Military Excellence: The Evolution of Operational Theory (New York: Frank Cass, 2004), 16.

${ }^{75}$ Georgii Samoilovich Isserson, The Evolution of Operational Art, translated by Bruce W. Menning (Fort Leavenworth: Combat Studies Institute Press, 2013), 48. 
correspond with the new conditions that define it." 76 While Isserson's focus is mostly on the idea of depth as time and space, there existed the budding elements of cognitive depth as seen today. However, the concept of perception and cognition continue to adapt the understanding of depth. Technology and advances in science have revolutionized the concepts of time and space, serving as a catalyst for opening eyes to their existing essence. ${ }^{77}$ Computers deconstruct the industrial age understanding of distance, allowing for individuals in two spatially diverse locations to connect instantly. Even the advent of aviation gives depth different meaning as it represents a change in cognition of what is capable, warping the human "conceptualization of dimension." ${ }^{78}$ It becomes apparent that the cognitive perception of depth, established on each mental map, transcends tangible seconds or inches. If cognitive shock is to work, then the designed approach must take advantage of the rival's perceptions of time and space - not simply on the physical manifestations of them. Cognitive shock will only result when depth is affected cognitively, with deep aspects of perception firmly striated in the mind are shaken and the purposeful mental gaps widen beyond immediate comprehension. The result is latency as the mind is unable to either carry out its current strategy or learn from the emerging ecology. Once latency occurs, depth in the more tangible sense manifests as additional space and time to exploit towards the gain of strategic aims. That is the ultimate goal of systemic cognitive fragmentation.

\footnotetext{
${ }^{76}$ Ibid.

${ }^{77}$ Paul Virilio, The Lost Dimension (Los Angeles: Semiotext(e), 2012), 39.

${ }^{78}$ Virilio, Lost Dimension 44.
} 


\section{Chapter Three}

\section{Systemic Cognitive Fragmentation}

Actually, the whole idea of the shock is to intervene within this gap, exploit this gap... broaden it or widen it or deepen it so he won't be able to actually use his deployment, his forces, his resources to exploit his logic.

- Shimon Naveh, Interview with author, Tel Aviv.

With an appreciation of how an organization develops a perception of reality and the way in which cognitive shock manifests it is now time to explore how one can harness this knowledge to create cognitive shock in order to gain depth in the achievement of strategic aims. However, this exploration will not result in a checklist for shocking an enemy nor will it present a solution for a specific situation. It will instead define critical aspects of systemic cognitive fragmentation necessary to exploit the cognitive depth of a rival's logic while facilitating the accomplishment of aims through the most efficient means possible.

Captured in the title of the concept is systemic thought to ensure the holistic appreciation of the emerging ecology and more importantly, the rival's system logic. A systemic approach to framing allows for the identification of the cognitive gap that exists between how the rival perceives the friendly element's strategy and the actual strategy used. This is achieved through a holistic appreciation and understanding of the relationships inherent with the system and the resulting rival's perception of reality manifested in the rival's system logic. An understanding of the rival's logic facilitates self-reflection on whether or not the current friendly strategy is relevant. The resulting innovation represents the novelty needed to widen the existing cognitive gap and create conditions for cognitive shock to occur. Yet, it is not one novel action that will provide the most shock. It is through the synchronized and simultaneous accomplishment of multiple unique actions that the rival's ability to comprehend and learn is fragmented. The preparatory work of deception enhances the magnification of fragmentation, further widening the cognitive gap prior to any action. 
Systemic Thought

There exists a tendency in western thought to seek an appreciation of things through the model of cause and effect. Relationships take on a linear nature, providing a convincing appreciation for the world and simplicity to complex issues. With a “means-end” relational understanding, the idea of controlling chaos becomes manageable and desirable. ${ }^{79}$ However, the world is anything but linear and systemic thought is critical to appreciating it. Systemic thought provides a way to represent reality as an open and complex adaptive system (CAS). Interrelationships between different entities within the system take on importance as these interactions determine emerging properties that transcend the simple causal-effect mindset. ${ }^{80}$ A holistic understanding emerges with an appreciation that no one actor within the system acts alone. Both internal and external stimuli affect and influence his cognitive processes with the resulting logic one of a systemic nature. ${ }^{81}$ More importantly, the discourse inherent in the various interactions and its reciprocal effect on each entity takes precedence. It is when emerging properties are focused on without an appreciation for their relationship to the whole that context is lost in understanding why the property originally emerged. With a loss of context, an aesthetic quality critical to a holistic appreciation of true reality is loss. ${ }^{82}$ The original tension between complementary, yet divergent elements is lost and with it the ability to recognize the cognitive

${ }^{79}$ François Jullien, A Treatise on Efficacy: Between Western and Chinese Thinking, translated by Janet Lloyd (Honolulu: University of Hawai’I Press, 2004), 37.

${ }^{80}$ Frans P.B. Osinga, Science, Strategy and War: The Strategic Theory of John Boyd (New York: Routledge, 2007), 95.

${ }^{81}$ Shimon Naveh and Jim Schneider and Timothy Challans, The Structure of Operational Revolution: A Prolegomena (Leavenworth: Booz Allen Hamilton, 2009).

${ }^{82}$ Harold G. Nelson and Erik Stolterman, The Design Way: Intentional Change in an Unpredictable World (Cambridge, MA: MIT Press, 2012), 183. 
gap present in reducing the tension. ${ }^{83}$ Systemic thought allows an observer to step back from the tactical level details and realize the whole.

For systemic cognitive fragmentation, systemic thought provides the way to frame the emerging ecology in its holistic form. It provides the context to understand the rival's logic and how the framed environment affects it. ${ }^{84}$ The rival system's logic replaces the older view of a static strategy that does not change. With the discovered logic comes an appreciation for the cognitive gap existent in how the rival perceives reality and true reality, providing the rival's critical vulnerability that is most susceptible to cognitive shock. ${ }^{85}$

The knowledge of the rival's system logic facilitates another significant ability: reflection. Reflection is essentially "an act of turning back upon ourselves" and allows the reflector to discover his own cognitive gap. ${ }^{86}$ Shimon Naveh describes the process as "building scaffolding” that allows someone to climb above the details and view their existing epistemology ${ }^{87}$ With an appreciation for the emerging ecology and the rival system’s logic, an evaluation occurs on whether or not the current strategy and accepted way of conducting operations is relevant. If it is not, then recalibration occurs, incorporating the new conceptual lens into the mental maps. ${ }^{88}$ This process of reciprocity allows for self-reflection, which in turn creates

${ }^{83}$ Nelson, The Design Way: Intentional Change in an Unpredictable World , 183. Zvi Lanir and Gad Sneh discuss the concept of complementary divergence in their publication, The New Agenda of Praxis. Complementary divergence represents the reciprocal relationship that exists in concepts often labeled as opposites such as hot and cold or light and dark. Instead of focusing on the differences, Lanir suggests understanding how each concept defines the other and gives each meaning. It is when only one concept is focused on that Harold Nelson suggests the context of its true meaning is lost.

${ }^{84}$ Shimon Naveh, interview by author, Tel Aviv, Israel, January 22, 2015.

${ }^{85}$ Ibid.

${ }^{86}$ Humberto Maturana and Francisco J. Varela, The Tree of Knowledge: The Biological Roots of Human Understanding (Boston: Shambhala, 1998), 24.

${ }^{87}$ Naveh, interview by author. 
innovation in the creation of a strategy. Innovation begins with discovery of the novel, or unique, based on the emerging ecology examined during systemic thought.

Growing Novelty Out of the Mental Voids

John Boyd asserted that novelty “is produced by a mental/physical feedback process of analysis and synthesis that permits us to interact with the world so that we can comprehend, cope with, and shape that world as well as be shaped by it." ${ }^{89}$ The mental/physical feedback process mentioned correlates to the mind's processing of new information and the creation and modification of mental maps. The potential for novelty exists in the mental gaps inherent in the compartmentalized way of processing information using social constructs. It is most likely that novelty is completely missed as the mind forces new inputs into an existing category, creates a new category without requisite contemplation (reference the emergence of hybrid warfare as the way to conceptualize the mixing of two, socially distinct types of existing warfare), or simply ignores the new input and allows it to fall deep into the mental gaps. ${ }^{90}$ However, when the creative mind embraces ambiguity, it explores the mental voids and novelty emerges out of the ill-defined and non-compartmentalized information. ${ }^{91}$

Ambiguity represents the space in which novelty will occur, a metaphorical blank piece of paper with a "world of possibilities."92 It also represents a "spatial twilight zone” in which the

${ }^{88}$ Naveh, Schneider, and Challans, The Structure of Operational Revolution: A Prolegomena, 31.

${ }^{89}$ Osinga, Science, Strategy and War: The Strategic Theory of John Boyd, 104.

${ }^{90}$ Zerubavel, The Fine Line, 6.

${ }^{91}$ Tony Veale, Kurt Feyaerts and Charles Forceville, ed., Creativity and the Agile Mind: A Multi-disciplinary Study of a Multi-faceted Phenomenon (Boston: De Gruyter, 2013), 23.

${ }^{92}$ Peter Turchi, Maps of the Imagination: The Writer as Cartographer (San Antonio: Trinity University Press, 2004), 28. 
boundaries and striated lines of mental maps are blurred in reduced levels of certainty. ${ }^{93}$ A lack of certainty conjures images of chaos and the loss of control that organizations fear most. ${ }^{94}$ However, it is in the undefined spaces that innovation occurs, embracing the increased possibilities presented through a lack of definition. Ambiguity also lies in the rival's cognitive gap and the lack of thought inherent in the void. When strategy emerges from taking advantage of the rival's mental void, it presents an almost unpredictable force that vastly increases the chance of cognitive shock. Novelty, however, does not need to be the creation of a completely different way of doing things. Instead, it represents the unexpected. The soccer player that shoots with his left foot when he tends to use his right presents novelty in his approach. The creation of the unpredicted strategy shares reciprocity with the rival's cognitive gap. The created strategy is only novel when it is unexpected to the rival.

There is a guiding constraint to novelty needed to ensure that it is achievable. It is important to remember that "at the heart of creativity lie constraints: the very opposite of unpredictability." 95 The constraint relates directly to the capabilities and resources available. A creative approach may call for novelty in equipment used, but is useless if the equipment does not exist or is not readily obtainable. Even more important is the ability for an organization and those members that will execute a given approach to comprehend what is required. Design and action often result in the creation of a new understanding and an associated new language with unique semantics. The new semantic may differ from the traditional understanding of a word that is captured and embraced in the social knowledge. ${ }^{96}$ This presents an issue in requiring those

\footnotetext{
${ }^{93}$ Eviatar Zerubavel, The Fine Line: Making Distinctions in Everyday Life (Chicago: University of Chicago Press, 1993), 35.

${ }^{94}$ Harold G. Nelson, “Simply Complex by Design,” Performance Improvement Quarterly 20, no. 2 (2007) 103.

${ }^{95} Z v i$ Lanir and Gad Sneh, The New Agenda of Praxis (Tel Aviv: Praxis, 2000), 28.

${ }^{96}$ Reuven Ben-Shalom, interview by author, Jerusalem, Israel, January 22, 2015.
} 
outside of the design process to implement the strategy. Novelty must take into account the cognitive and tangible resources need to achieve it. Using common language associated with the existing epistemology to explain the novel approach ensures comprehension and the increased likelihood of the designed approach being utilized in its intended manner, further increasing the chances of cognitive shock occurring.

\section{Cognitive Swarming}

While a novel action is important, it is not be enough to overwhelm the rival. It requires multiple actions to exploit the cognitive depth of the rival. It also requires a reconceptualization of mass as a singular entity to a cognitive aspect. ADRP 3-0 defines mass as concentrating "the effects of combat power at the most advantageous place and time to produce decisive results." 97 The use of place and time in the singular suggest massing occurs at one point. However, the concept of swarming provides a different way of conceptualizing mass. Conjuring visions of bees, ants, or termites, swarming examines the concept of large groupings of soldiers in "networks of distributed intelligence" accomplishing tasks. ${ }^{98}$ It is through these smaller elements that "forces will be able [to] converge on all directions for offensive bursts thereby maximizing the shock effect." ${ }^{99}$ Instead of massing in the traditional sense at a specific point, massing occurs through synchronized and simultaneous action across the rival's depth. This presents the opportunity to inhibit the rival's ability to react effectively as multiple actions spread his attention and prevents reactive massing in a timely manner. When multiple actions are novel in how they take form, this then increases the surprise created and the learning induced latency required to

\footnotetext{
${ }^{97}$ Army Doctrine Reference Publication (ADRP) 3-0, Unified Land Operations (Washington, DC: Government Printing Office, 2012), 4-2.

${ }^{98}$ Bousquet, The Scientific Way of Warfare: Order and Chaos on the Battlefields of Modernity (New York: Columbia University Press, 2009), 210.

${ }^{99}$ Ibid., 213.
} 
react. While much is discussed in the pursuit of nano-technologies and other robotics that may serve as surrogates for human soldiers, the importance of swarming lies in its overarching concept. ${ }^{100}$ To overwhelm and cognitively fragment the rival's reality, multiple actions are required.

Deception

A critical aspect of nurturing the conditions for cognitive shock and the exploitation of the created depth is deception. As defined earlier, surprise presents itself when there is a mismatch in the perceived and presented reality. The greater the mismatch, the more latency occurs in the associated learning process and the more depth available to execute further actions. Deception provides a way to broaden the existing mental gap to increase the likelihood of shock occurring. The use of deception to drive surprise is nothing new and most militaries have a form of it incorporated into their standard procedures. However, the Soviet's integration of maskirovka (operational deception) in their theory of Deep Operations provides a thorough example of deception used to affect an enemy in depth. The primary purpose of maskirovka is "to amplify the effects of udar (operational shock), by means of manipulating surprise.” ${ }^{101}$ According to Naveh, the manipulation is "attained by a combination of psychological and mechanical acts, aimed at developing within the opposing command a certain state of mind that will both suit and encourage the actual implementation of the striking manoeuvre.” ${ }^{102}$ Disinformation was broadcast while certain units became decoys either to hide the true designs for the maneuver or to cause the adversary to reposition assets to the wrong location.

${ }^{100}$ Ibid.

${ }^{101}$ Shimon Naveh, In Pursuit of Military Excellence: The Evolution of Operational Theory (New York: Frank Cass, 2004), 27.

${ }^{102}$ Ibid. 
While there is a cognitive effect achieved through maskirovka, its primary manifestation relates to setting the conditions for the use of force. The concept of associative coherence provides a more practical manner of understanding how deception can achieve a focused cognitive effect. It occurs when "a self-reinforcing pattern of cognitive, emotional, and physical responses that is both diverse and integrated” yields through the creation of mental maps. ${ }^{103}$ Once coherent correlations are determined, input received outside of this coherence falls by the wayside, forced either into the perceived reality or into the mental gaps. ${ }^{104}$ While systemic cognitive fragmentation exploits cognitive gaps, deception works to reinforce associative coherence already present. This works to bolster the rival's perceived reality and to conceal any actions or intent that do not fit. Deception ensures that the chasms spanning the different realities increase at a rate that defies suspicion and ensures the greatest amount of cognitive shock resulting from multiple novel actions. 2013), 51.

${ }^{103}$ Daniel Kahneman, Thinking, Fast and Slow (New York: Farrar, Straus and Giroux,

${ }^{104}$ Daniel Kahneman, “The Marvels and the Flaws of Intuitive Thinking: Edge Master Class 2011,” Thinking: The New Science of Decision-Making, Problem-Solving, and Prediction, edited by John Brockman (New York: Harper Perennial, 2013), 395. 


\section{Conclusion}

\section{Fragmenting the Doors of Perception}

For even in the past not a few battles have been won by surprise rather than by force of arms, and if a battle can be won without suffering loss, surely this is the most economical, if not the most traditional, way of gaining the strategical object.

- J.F.C. Fuller, On Future Warfare

The French philosopher François Jullien illuminates the difference between western and eastern thought on military foresight in his book, A Treatise on Efficacy. While he postulates that a majority of western texts focus on using anticipation for prevention of likely threats, eastern focus is on observing potential opportunity through developing tendencies. ${ }^{105}$ The ideal Chinese general “sets up no hypotheses, makes no attempt to calculate what is probable,” but instead, “all his skill lies in the earliest possible detection of the slightest tendencies that may develop.” ${ }^{106}$ The identification of forming potential allows the general to focus his approach towards achieving his aims. The developing tendency can be viewed as a tiny fissure that opens up and deepens into a crack or gap. ${ }^{107}$ The gap represents the weakness in the adversary and the most efficacious "spot" to attack. ${ }^{108}$ The adversary's inevitable defeat occurs with "simply push into the crack and allow it to develop.”109110

\footnotetext{
${ }^{105}$ François Jullien, A Treatise on Efficacy: Between Western and Chinese Thinking, translated by Janet Lloyd (Honolulu: University of Hawai’i Press, 2004), 68.

${ }^{106}$ Ibid., 69.

${ }^{107}$ Ibid.

${ }^{108}$ Spot is in quotations because the developing crack is not necessarily a spatially related or tangible thing. In the case of cognitive shock, the crack is the cognitive gap that exists in the rival's logic.

${ }^{109}$ Jullien, A Treatise on Efficacy: Between Western and Chinese Thinking, 70.

${ }^{110}$ Chinese Expression Tue. jian 推間
} 
Ultimately, this is what systemic cognitive fragmentation attempts to do. It provides a way to holistically view the emerging ecology for the purpose of identifying the rival's logic and cognitive gap through the use of systemic thought. The theory also provides a way to determine the most efficient and appropriate manner to envision novel approaches for the given situation. Through multiple, novel actions the practitioner creates the greatest opportunity to cause cognitive shock in the rival and fragment his ability to react and learn. The resulting depth in time and space furthers the ability to exploit opportunities presented with a shocked rival. The amount of resources and human casualties needed to achieve contested aims decreases. It is through this process that systemic cognitive fragmentation provides the most efficient and effective manner to create cognitive shock and exploit the emerging depth towards achieving strategic aims.

As with any theory, caution is necessary when transitioning into practice. While systemic thought provides a holistic manner to determine how the rival views the environment and his associated strategy, it is never possible to know completely what the rival's true perception really is. ${ }^{111}$ It is also dangerous to assume the rival's logic will not eventually adapt with changes to the environment, as even cognitive shock cannot prevent learning from eventually occurring. This requires the practitioner of systemic cognitive fragmentation to catalogue and revisit the assumptions required to develop his understanding of the system. He must also revisit them often to determine if they are still valid. In the event that the assumptions are no longer applicable, then a reevaluation of the framed rival's logic is required. This may require a complete reframing and that is completely acceptable as the practitioner is also going through a learning process. The real danger occurs when information already captured on mental maps trumps that of new inputs that contradict the established model.

The theory of systemic cognitive fragmentation is bigger than the limited size of a monograph and it will require additional develop and research. While cognitive processes are

\footnotetext{
${ }^{111}$ Shimon Naveh, interview with author, Tel Aviv, Israel, January 22, 2015.
} 
easily stated in short form, the true artifacts originating from organizations still present debate from organizational theorists. A better understanding of how an organization's logic manifests in an observable manner will provide a better understanding of what might guide systemic analysis of an emerging ecology. An examination also needs to occur into how the theory may work as a whole of government approach outside of just a military perspective. Cognitive shock transcends mere military induction as diplomatic or informational actions can also cause fundamental surprise. If an overarching strategy is designed through the use of a unifying theory to fragment the rival's logic, then the achievement of strategic aims is that much more likely. This requires a transition from acting only on the tangible and the focus of time and space. Cognition presents the unifying aspect of warfare and discourse in general. It is he who appreciates the propensity inherent with cognition that sets him in the greatest position of relative advantage. 


\section{Bibliography}

Adhami, Mundher. “Cognitive and Social Perspectives on Surprise.” Mathematical Teaching 200 (January 2007): 34-36.

Adler, Jonathan E. “Surprise.” Educational Theory 58, no. 2 (2008): 149-173.

Army Doctrine Reference Publication 3-0, Unified Land Operations. Washington, DC: Government Printing Office, 2012.

Avidor, Gideon. Interview by author. Tel Aviv, Israel. January 19, 2015.

Ben-Shalom, Reuven. Interview with author. Jerusalem, Israel. January 22, 2015.

Berger, Peter L. and Luckman, Thomas. The Social Construction of Reality: A Treatise in the Sociology of Knowledge. New York: Anchor Books, 1967.

Boden, Margaret. “Creativity and Unpredictability.” Stanford Humanities Review 4, no. 2 (June 1995): 123-139.

Bousquet, Antoine. The Scientific Way of Warfare: Order and Chaos on the Battlefields of Modernity. New York: Columbia University Press, 2009.

Brockman, John, ed. Thinking: The New Science of Decision-Making, Problem-Solving, and Prediction (New York: Harper Perennial, 2013).

Campbell, Ginger. Host. "Discussion of Self Comes to Mind: Constructing the Conscious Brain by Antonio Damasio, PhD.” Brain Science Podcast. December 02, 2012. Accessed November 08, 2014. http://brainsciencepodcast.com.

. Host. "Interview with Dr. Michael Graziano, Author of Consciousness and the Social Brain.” Brain Science Podcast. April 15, 2014. Accessed February 13, 2015. http://brainsciencepodcast.com.

Clausewitz, Carl Von. On War. Edited and translated by Michael Howard and Peter Paret. Princeton: Princeton University Press, 1984.

Damasio, Antonio. Self Comes to Mind: Constructing the Conscious Brain. New York: Pantheon Books, 2010.

Deleuze, Gilles and Guattari, Félix. Nomadology: The War Machine. Translated by Brian Massumi. New York: Semiotext(e), 1986.

Dörner, Dietrich. The Logic of Failure: Recognizing and Avoiding Error in Complex Situations. Translated by Rita and Robert Kimber. New York: Metropolitan Books, 1996.

Fadok, David S. John Boyd and John Warden: Air Power's Quest for Strategic Paralysis. Maxwell Air Force Base: Air University Press, 1995.

Foreign Broadcast Information Service. USSR Report: Provisional Field Regulations for the Red Army. Springfield, VA: National Technical Information Service, 1986. 
Freedman, Lawerence. Strategy: A History. New York: Oxford University Press, 2013.

Fuller, J.F.C. On Future Warfare. London: Sifton Praed \& Co., LTD, 1928.

Gaddis, John Lewis. The Landscape of History. Oxford: Oxford University Press, 2002.

Gerras, Stephen J. Thinking Critically About Critical Thinking: A Fundamental Guide for Strategic Leaders (Carlisle: US Army War College, 2008).

Gharajedaghi, Jamshid. Systems Thinking: Managing Chaos and Complexity. Boston: Morgan Kaufmann, 2011.

Glantz, David M. Soviet Military Operational Art: In Pursuit of Deep Battle. Portland: Frank Cass, 1991.

Graziano, Michael S. A. Consciousness and the Social Brain. New York: Oxford University Press, 2013.

Guattari, Félix. Schizoanalytic Cartographies. Translated by Andrew Goffey. New York: Bloomsbury, 2013.

Harrison, Richard W. Architect of Soviet Victory in World War II: The Life and Theories of G.S. Isserson. Jefferson, NC: McFarland \& Company, Inc., Publishers, 2000.

Hirsch, Gal. Interview by author. Tel Aviv, Israel. January 19, 2015.

Horstmann, Gernot. "Latency and Duration of the Action Interruption in Surprise.” Cognition and Emotion 20, no. 2 (2006): 242-273.

Huxley, Aldous. The Doors of Perception. New York: Harper Perennial, 2009.

Isserson, Georgii Samoilovich. The Evolution of Operational Art. Translated by Bruce W. Menning. Fort Leavenworth: Combat Studies Institute Press, 2013.

Jervis, Robert. System Effects. Princeton, N.J.: Princeton University Press, 1997.

Jullien, François. A Treatise on Efficacy: Between Western and Chinese Thinking. Translated by Janet Lloyd. Honolulu: University of Hawai'i Press, 2004.

. The Propensity of Things: Toward a History of Efficacy in China. Translated by Janet Lloyd. New York: Zone Books, 1999.

Kahneman, Daniel. Thinking, Fast and Slow. New York: Farrar, Straus and Giroux, 2013.

Kiras, James D. Special Operations and Strategy: From World War II to the War on Terrorism. New York: Routledge, 2006.

Knowles, Malcolm S. and Holton, Elwood F. and Swanson, Richard A. The Adult Learner: The Definitive Classic in Adult Education and Human Resource Development. New York: Routledge, 2012. 
Krippendorff, Klaus. The Semantic Turn: A New Foundation for Design. New York: Taylor \& Francis Group, 2006

Lawson, Bryan. How Designers Think. London: Butterworth Architecture, 1990.

Lakoff, George and Johnson, Mark. Metaphors We Live By. Chicago: The University of Chicago Press, 2003.

Lambert, A. P. N. The Psychology of Air Power. London: Royal United Services Institute for Defence Studies, 1995.

Lanir, Zvi. “Fundamental Surprises.” PhD diss., University of Tel Aviv. Accessed November 01, 2014. http://csel.eng.ohiostate.edu/courses/ise817/papers/Fundamental_Surprise1_final_copy.pdf. . Interview by author. Tel Aviv, Israel. January 21, 2015. and Sneh, Gad. The New Agenda of Praxis. Tel Aviv: Praxis, 2000.

Leonhard, Robert R. Fighting by Minutes: Time and the Art of War. Westport: Praeger, 1994.

Lorini, Emiliano and Castelfranchi, Cristiano. "The Cognitive Structure of Surprise: Looking for Basic Principles.” Topoi 26, no. 1 (March 2007): 133-149.

Mann, Edward C. and Endersby, Gary and Searle, Thomas R. Thinking Effects: Effects-Based Methodology for Joint Operations. Maxwell Air Force Base: Air University Press, 2002.

Maturana, Humberto R. and Varela, Francisco J. The Tree of Knowledge: The Biological Roots of Human Understanding. Boston: Shambhala, 1998.

Merhav, Reuven. Interview by author. Jerusalem, Israel. January 22, 2015.

Mets, David R. The Air Campaign: John Warden and the Classical Airpower Theorists. Maxwell Air Force Base: Air University Press, 1999.

Naveh, Shimon. In Pursuit of Military Excellence: The Evolution of Operational Theory. New York: Frank Cass, 1997. . Interview by author. Tel Aviv, Israel. January 22, 2015. . “Systemic Operational Design 2009,” PowerPoint Presentation. and Schneider, Jim and Challans, Timothy. The Structure of Operational Revolution: A Prolegomena. Leavenworth: Booz Allen Hamilton, 2009.

Newman, David. Boundaries, Territory and Postmodernity. Portland, OR: Frank Cass, 2002.

Osinga, Frans P.B. Science, Strategy and War: The Strategic Theory of John Boyd. New York: Routledge, 2007. 
Schön, Donald A. The Reflective Practitioner. New York: Basic Books, 1983.

Simon, Herbert A. "Bounded Rationality and Organizational Learning.” Organization Science 2, no.1 (February 1991): 125-134.

Simpkin, Richard. Deep Battle: The Brainchild of Marshal Tukhachevskii. New Delhi: Natraj Publishers, 2012.

Sun Tzu. Art of War. Translated by Ralph D. Sawyer. New York: Basic Books, 1994.

Taerk, Gary. "Moments of Spontaneity and Surprise: The Nonlinear Road to Something More.” Psychoanalytic Inquiry 22, no. 5 (2002): 728-739.

Taleb, Nassim Nicholas. Antifragile: Things That Gain From Disorder. New York: Random House, 2014. . The Black Swan: The Impact of the Highly Improbable. New York: Random House, 2007.

Virilio, Paul. Lost Dimension. Los Angeles: Semiotext(e), 2012.

Warden, John A. The Air Campaign. New York: toExcel, 2000.

Weick, Karl E. and Sutcliffe, Kathleen M. and Obstfeld, David. "Organizing and the Process of Sensemaking.” Organization Science 16, no. 4 (July-August 2005): 409-421.

Wilkinson, Spenser. The Brain of an Army: A Popular Account of the German General Staff. London: Constable \& Company LTD, 1913.

Zerubavel, Eviatar. Hidden in Plain Sight: The Social Structure of Irrelevance. New York: Oxford University Press, 2015. . Social Mindscapes: An Invitation to Cognitive Sociology. Cambridge: Harvard University Press, 1999.

. The Fine Line: Making Distinctions in Everyday Life. Chicago: The University of Chicago Press, 1993. 